\title{
И.Е. Яловега
}

\section{МЕЖДУНАРОДНЫЙ РЕЙТИНГ ВУЗА: КАЧЕСТВО ОБРАЗОВАНИЯ ИЛИ СУБЪЕКТИВНОЕ ДОМИНИРОВАНИЕ?}

\begin{abstract}
Рассмотрена проблема оценки качества образования международными рейтингами вузов. Приведены основные, признанные мировым сообществом, глобальные рейтинги лучших университетов, проанализированы критерии, используемые различными рейтингами для оченки «качества» университета, выявлено, что такое «лучиий университет» по версии рейтингов, представлены варианты измерения «качества» высшего образования. Проведено собственное исследование выпускников томских вузов различных факультетов. На основе полученных данных был сделан вывод о том, как используют подобные рейтинги сами вузы, а также абитуриенты и их родители и кому они больие необходимы.

Ключевые слова: качество образования, глобальные рейтинги вузов, научная деятельность университета, конкурентоспособность вузов, концепция экспорта образовательных услуг РФ.
\end{abstract}

Что представляют собой рейтинги лучших университетов в мире? Как они работают: есть ли возможность благодаря попаданию в рейтинг привлечь больше студентов, а значит, ресурсов? Получат ли выгоды не только университеты, но и города, где они расположены (дополнительный экономический и социальный эффект: рабочие места и налоги), либо разработка рейтинга дает дополнительный «промоушн» университетам, тем самым обеспечивая конкурентное преимущество перед другими университетами? Данные вопросы обусловили цель и задачи нашего исследования. Чтобы оценить, являются ли рейтинги показателем качества образования; действительно ли набор критериев рейтинга отражает понятие «лучший университет», были поставлены следующие задачи:

1) проанализировать критерии, используемые различными рейтингами, для оценки «качества» университета;

2) выявить, что такое «лучший университет»;

3) представить варианты измерения «качества» высшего образования;

4) оценить, являются ли вузы-лидеры действительно «лучшими университетами», учитывает ли рейтинг вуза «качество» высшего образования;

5) обосновать необходимость нахождения российских университетов в рейтингах вузов с целью реализации концепции экспорта образовательных услуг РФ на период 2011-2020 гг.

Для реализации поставленной цели и решения задач рассмотрим основные, признанные мировым сообществом, глобальные рейтинги лучших университетов и на основе анализа полученных результатов сделаем вывод об объективности оценки показателя качества высшего образования данными рейтингами, критериях оценки и ответим на вопрос: действительно ли данные критерии отражают понятие «лучший университет». 
1.THE WorldUniversityRankings - рейтинг лучших университетов в мире по версии британского издания TimesHigherEducation (THE). Анализ деятельности высших учебных заведений данного рейтинга складывается из 13 показателей. Основными оценочными критериями являются международная студенческая и преподавательская мобильность, количество международных стипендиальных программ, уровень научных исследований, вклад в инновации, цитируемость научных статей, уровень образовательных услуг и т.д. Все оценки нормированы по максимуму и приведены к 100-балльной шкале.

Из этого рейтинга видно, что большое внимание уделяется научным исследованиям и инновациям, что, в свою очередь, улучшает качество и уровень образования, а это также оценивается как один из критериев данного рейтинга. Максимальную долю (32,5\%) имеет критерий «цитируемость научных публикаций», формализованный относительно разных областей исследований (для анализа используются данные 12 тысяч научных журналов за пятилетний период) (табл. 1). Лидерами по данному критерию являются вузы США.

Таблица 1. Рейтинг 10 лучших университетов мира по версии TimesHigherEducation [1]

\begin{tabular}{c|c|c|c}
\hline Рейтинг & Университет & Страна & Оценка \\
\hline 1 & California Institute of Technology & США & 94,3 \\
\hline 2 & Harvard University & США & 93,3 \\
\hline 2 & University of Oxford & США & 93,2 \\
\hline 4 & Stanford University & Великобритания & 92,9 \\
\hline 5 & University of Cambridge & США & 91,0 \\
\hline 6 & Massachusetts Institute of Technol- & & 90,9 \\
\hline 7 & Princeton University & США & 89,5 \\
\hline 8 & University of California, Berkeley & США & 87,5 \\
\hline 10 & Imperial College London & Великобритания & 87,5 \\
\hline
\end{tabular}

Рейтинг WorldUniversityRankings публикуется ежегодно с 2010 г. на основе анализа деятельности 400 вузов. Лидирующие позиции (45 университетов) среди первых 100 вузов в этом рейтинге занимают вузы США, в том числе они явные лидеры в первой десятке. Следом идет Великобритания - 11 университетов, Нидерланды - 6, Германия - 6, Австралия - 5, Канада - 4, Швеция, Швейцария и Южная Корея - по 3. Вузы Японии, Сингапура, Франции, Гонконга, Китая, Турции, Бельгии и Италии также присутствуют в рейтинге ТОП-100, но их 1-2.

Россия расположилась посередине таблицы данного рейтинга, занимая 226-250-е места, деля их с университетами Испании, Турции, Германии, Ка- 
нады и др. с единственным российским университетом, вошедшим в этот рейтинг, - МГУ им. М.В. Ломоносова.

2. QS WorldUniversityRankings - рейтинг лучших высших учебных заведений мира по версии британской консалтинговой компании QuacquarelliSymonds (QS). Данная компания анализирует деятельность вузов, выбирая из них ТОП-50 на основе оценки университетов по таким показателям, как активность и качество научно-исследовательской деятельности, мнение работодателей и карьерный потенциал, преподавание и интернационализация.

В отличие от предыдущего рейтинга, здесь самый большой вес имеют следующие статьи: индекс академической репутации (по результатам опроса) - 40\%; соотношение профессорско-преподавательского состава и численности обучающихся - 20\%; соотношение индекса цитирования научных статей (база данных Scopus) преподавательского состава и его численности $20 \%$ (табл. 2).

Таблицุа 2. Рейтинг 10 лучших университетов по версии QS [2]

\begin{tabular}{c|c|c|c}
\hline \multirow{2}{*}{ Рейтинг } & Университет & Страна & Оценка \\
\hline 1 & Massachusetts Institute of Technology (MІT) & США & 100,0 \\
\hline 2 & Imperial College London & Великобритания & 99,4 \\
\hline 2 & University of Cambridge & Великобритания & 99,4 \\
\hline 4 & Harvard University & США & 99,3 \\
\hline 5 & UCL (University College London) & Великобритания & 99,2 \\
\hline 5 & University of Oxford & Великобритания & 99,2 \\
\hline 7 & Stanford University & США & 98,3 \\
\hline 9 & California Institute of Technology (Caltech) & США & 97,1 \\
\hline 10 & Princeton University & США & 96,6 \\
\hline
\end{tabular}

Рейтинг лучших высших учебных заведений мира 2014 г. по версии QS (QS World University Rankings), хоть и учитывает меньше вузов, чем в предыдущем рейтинге, не меняет картины распределения стран на мировом рынке образования.

3. Академический рейтинг университетов мира составляется и в Шанхайском университета Цзяо Тун. Основной акцент в нем делается на следующие показатели:

- размер вуза (10\%);

• выпускники - лауреаты Нобелевской или Филдсовской премии (10\%); 
• сотрудники - лауреаты Нобелевской или Филдсовской премии (20\%);

•цитируемость исследователей в 21 категории (20\%);

- статьи, опубликованные в журналах Nature и Science (20\%);

-индекс Института научной информации (Institute for Scientific Information - ISI) Science Citation Index и Social Sciences Citation Index цитирования для естественных и гуманитарных наук;

•индекс ведущих журналов Arts and Humanities Citation Index (20 \%) (табл. 3).

Из вышеизложенного видно, что данный рейтинг направлен на изучение и анализ мировых вузов с точки зрения научного подхода, о чем свидетельствуют такие показатели, как число лауреатов премий, качество статей и индексы цитирования.

Таблица 3. ТОП-10 по версии Шанхайского университета Цзяо Тун [3]

\begin{tabular}{c|c|c|c}
\hline Рейтиг ARWU & Университет & Страна & Оценка \\
\hline 1 & Harvard University & США & 700 \\
\hline 2 & Stanford University & США & 70,5 \\
\hline 3 & Massachusetts Institute of Technology & США & 70,1 \\
\hline 4 & University of California, Berkeley & США & 69,2 \\
\hline 5 & University of Cambridge & Великобритания & 60,7 \\
\hline 9 & Princeton University & США & 60,5 \\
\hline 9 & California Institute of Technology & США & СШикобритания \\
\hline Columbia University & СШіversity of Chicago & 57,4 \\
\hline
\end{tabular}

В данном рейтинге, как и в предыдущих, в ТОП-100 лидируют - их 52 университеты США. В Великобритании -8 университетов, в Германии -5 . Далее в списке располагаются страны с 4 университетами - Швейцария, Канада, Франция, Австралия, Нидерланды. Три университета в Японии, Швеции. В Дании, Израиле, Бельгии в рейтинге по 2 вуза. И замыкает список стран, имеющих один вуз в данном рейтинге, Норвегия, Финляндия, Россия ${ }^{1}$.

Основные мировые рейтинги в области образования самое главное и самое весомое место отдают научной деятельности, которую измеряют цитируемостью научных статей и академической репутацией. В Шанхайском рей-

\footnotetext{
${ }^{1}$ Московский государственный университет им. М.В. Ломоносова - 84-е место в рейтинге.
} 
тинге важны лауреаты премий, а в рейтинге TimesHigherEducation - вклад в инновации.

Прямого доказательства того, как данные исследования оказывают влияние на производство, инновации, экономику страны или мира в целом, нет. Также отсутствует в рейтингах измерение эффективности вложений в научную деятельность университетов, хотя это самые признанные рейтинги на сегодняшний день среди мирового сообщества высшего образования. Если и затрагивается какой-то из этих показателей, то не напрямую, а косвенно, и в основном через оценку университетов экспертами, а не фактами и конкретными данными.

Ректоры МГУ и ВШЭ (и не только они) считают, что «качество» образования прямого отношения к глобальным рейтингам не имеет, ссылаясь на то, что в рейтингах отражен достаточно узкий спектр показателей, который не может выявить уровень качества образования в вузе в целом [4]. Поэтому для оценки деятельности вуза необходимо включать больше параметров, связанных с определением качества образования.

По словам директора отделения Гринвичского университета по международным и региональным связям, нужно составлять рейтинг отдельных предметов (дисциплин) вуза, так как, например, по общему рейтингу британских университетов их университет находится на 60-м месте, а по ряду дисциплин (инженерные и экономические) входит в первую десятку [5].

Стоит согласиться с данным мнением ректоров, так как, если рассматривать мировые рейтинги, «картина» лучших университетов мира получается неполной и весьма неоднозначной. Шанхайский рейтинг достаточно жесткий; такой показатель, как, например, выпускники вуза - нобелевские лауреаты - достаточно сложен для достижения, да и показывает не университет в целом, а достижение отдельных участников процесса. THE - рейтинг не фактов, а оценок. QS - еще более мягкий, чем THE; он включает оценки востребованности выпускников, признание этого вуза в обществе. Получается, что это во многом рейтинг мнений экспертов, рейтинг известности.

Но в любом случае рейтинги весьма полезны, а неприятные - полезны вдвойне. Здесь имеет место стимулирование, которое дает возможность увеличивать уровень конкуренции и проникать в глобальное пространство высшего образования [6].

Не следует также забывать о том, что одной из основных задач вуза является подготовка студентов для успешной реализации себя на рынке труда. Этот показатель - трудоустройство выпускников - также не учитывается в той степени, в какой это необходимо. Например, в рейтинге Universitas 21 уровень востребованности выпускников учитывается, но наряду с эффективностью научной работы и наличием в стране университетов с мировым именем [7]. Научная деятельность и продвижение науки - это важно, но также важен процесс производства, торговли и реализации, где должны работать профессионалы. Эти показатели должны рассматриваться в совокупности, так как без науки нет практики, но и практика без теории возможна не в полной мере.

Основными целями любого университета являются: 
• обеспечение развития университета с перспективой вхождения в число ведущих вузов мира;

•достижение лидирующих позиций - запланированной совокупности показателей - в списке лучших университетов;

-усиление интеграции в международное образовательное и научное пространство, основанное на системном развитии партнерских отношений с ведущими мировыми образовательными, научными и бизнес-партнерами;

• обеспечение языковой компетенции сотрудников и студентов [8].

Оценивая цели университета, видно, что рейтинги в основном соответствуют поставленным целям. Получается, идет конкуренция между университетами за звание «лучшего», а потом, как следствие, за студентов. Но о качестве образования ни слова.

В 2010 г. социологи выяснили, какие цели преследуют современные молодые люди при получении высшего образования. Опрошено 1600 человек в 140 населенных пунктах в 42 областях, краях и республиках России. По результатам опроса выяснилось, что самая важная цель во время обучения в вузе - хорошо учиться и стать профессионалом; на нее сослались 59\% респондентов. Второй по значимости аспект - поиск будущей работы и установление контактов с потенциальными работодателями (34\%). На третьем месте по важности - приобретение навыков взрослого поведения (25\%). Меньшее значение студенты придают участию в студенческих мероприятиях и реализации себя как творческой личности (16\%), поиску друзей и будущего супруга (9\%), веселому времяпрепровождению (6\%) [9].

На основе приведенных данных социологического исследования делаем вывод, что потребителям важно стать компетентными специалистами в своем деле, чтобы с помощью своих навыков, знаний и умений они могли найти себе работу, которая бы способствовала их профессиональному росту в интересующей их области. О рейтингах, судя по имеющимся данным, опрошенные респонденты не задумываются.

Нами было проведено исследование среди выпускников томских вузов различных факультетов о том, руководствуются ли студенты при выборе вуза рейтингами университетов. Из 37 опрошенных человек только один не слышал про существование подобных рейтингов. Для $38 \%$ респондентов рейтинги повлияли на выбор университета, так как при принятии решения они руководствовались рейтингами. Для 59\% выпускников рейтинги не играли никакой роли и не влияли на принятие решения. Оставшиеся $3 \%$ респондентов оставили вопрос без ответа.

Для большинства опрошенных выпускников решающими факторами при выборе университета были: направление университета, перспективы успешного трудоустройства, уровень вуза, уровень преподавания, нужная специальность (40,5\% опрошенных). Мнение окружающих, учащихся и выпускников важно было для 16,2 \% опрошенных, за престиж университет выбрали $13,5 \%$, а $10,8 \%$ уже заранее знали, куда будут поступать. От ответа воздержались $19 \%$ (7 человек).

На вопрос «Влияет ли рейтинг на выбор вуза?» 62,2\% респондентов дали уверенный ответ, что рейтинг влияет на выбор родителями университета, так как престижный университет, по их мнению, дает возможность получения 
более качественного образования, а следовательно, более перспективной работы. Остальные $18,9 \%$ считают, что рейтинг не влияют на выбор вуза ни абитуриентов, ни их родителей; еще столько же воздержалось от ответа.

Для основной аудитории респондентов $(59,5 \%)$ реальная цель существования рейтинга - это конкуренция между вузами, борьба за финансирование, прибыль, PR, «отмывание денег» и поддержание престижа. По мнению $24,3 \%$, рейтинги нужны для того, чтобы была возможность оценить качество и уровень образования, выявить лучшие университеты, т.е. оценить университеты «по достоинству». Всего $8,1 \%$ опрошенных считают, что эти рейтинги созданы для абитуриентов и их родителей, оставшаяся часть $(8,1 \%)$ от ответа воздержалась. К «борьбе за прибыль» и «оценке качества образования» респонденты добавляли, что также рейтинги делаются для помощи абитуриентам и их родителям, хотя первоначально они указывали на значимость «платы за обучение».

На вопрос о том, какими должны быть цели университета, все респонденты, кроме одного воздержавшегося, ответили, что основными целями университета должны быть следующие: качественное образование; наличие современных технологий, способствующих получению качественного образования; на этой базе должны выпускаться компетентные специалисты с возможностью достойного трудоустройства. Респонденты отметили, что при обучении в университетах недостаточно практики и что теоретические знания, получаемые в университете, далеки от реальных потребностей предприятий, а также то, что без опыта трудно найти работу.

Из данного исследования можно сделать вывод, что для самих абитуриентов крайне важно, чтобы университет не только давал качественное образование, но и воспитывал активную жизненную позицию, вовлекал в активную общественную деятельность, способствовал формированию и развитию физической и культурной деятельности студентов. Главным критерием для абитуриентов и их родителей является возможность хорошего и перспективного трудоустройства.

Возможно, необходимо создать российский рейтинг, где вузы России смогли бы, выполняя цели Концепции экспорта образовательных услуг РФ, конкурировать не только за звание «лучшего» университета, но также и за лучших студентов. Этими целями, в частности, являются:

-повышение качества, привлекательности и конкурентоспособности российской системы образования в мировом и региональном образовательном пространстве;

- обеспечение эффективного участия России в глобальном и важнейших региональных процессах развития образования;

•повышение доли экспорта образовательных услуг в российском ВВП [10].

Среди задач по выполнению Концепции есть такие, как формирование инфраструктуры и институциональных условий мобильности студентов, преподавателей и исследователей всех уровней, а также внедрение современной системы квалификаций, которые сопоставимы со стандартами ЕС, ОЭСР и общеевропейского пространства высшего образования. Данные задачи относятся к повышению качества образования, но в рейтингах нет параметров 
соответствия или наличия сформированной инфраструктуры для мобильности, это идет, скорее всего, параметром «по умолчанию». Новый рейтинг, сформированный на показателях научной активности, оценке качества образования, востребованности выпускников и уровне трудоустройства, позволит российским вузам выполнить задачи Концепции. Первоначально имеет смысл разработать рейтинг только российских вузов, так как Концепция распространяется лишь на Россию. В последующем возможно совершенствование данного рейтинга, т.е. включение показателей оценки, которые будут затрагивать все мировое сообщество высшего образования.

Bывод. Самое важное для формирования рейтингов лучших университетов - это наличие научной деятельности. Показатели деятельности университета, включенные в рейтинги, не гарантируют привлечения лучших преподавателей, да и лучших студентов, так как они не оценивают качество образования, а следовательно, не являются решающим фактором для студентов в выборе вуза для обучения. Студентам, как и их родителям, интересны возможности «бюджетного» образования и хорошего трудоустройства. Этого рейтинги не учитывают, поэтому, скорее, носят для потребителей информативный характер, но не влияют на окончательный выбор места обучения. На наш взгляд, успешному обучению способствуют:

-преподаватели, знающие свой предмет и постоянно обновляющие свои знания, работающие в глобальном пространстве высшего образования;

•наличие инфраструктуры, необходимой для успешного обучения;

•возможность получения бюджетного обучения, грантов/стипендий не только на оплату обучения, но и на расходы на проживание и проезд;

• возможность академической мобильности;

•возможность хорошего трудоустройства.

Разумеется, такие показатели, как научная деятельность, индекс цитирования, индекс инновационного развития, имеют значение и должны учитываться в рейтингах, но наряду с другими вышеперечисленными показателями. Рейтинги не нужно абсолютизировать. Их нужно принимать во внимание.

\section{Литература}

1. The World University Rankings 2014-2015 [Electronic resource] // Официальный сайт «Times Higher Education». URL: http://www.timeshighereducation.co.uk/world-university-rankings/ 2014-15/world-ranking (access date: 19.01.2015).

2. Рейтинг лучших университетов мира 2014 QS [Электронный ресурс] // Сайт «Topuniversities». URL: http://www.topuniversities.com/university-rankings/world-university-rankings/2014\# sorting $=$ rank + region $=+$ country $=+$ faculty $=+$ stars $=$ false + search $=($ дата обращения: 19.01.2015).

3. Академический рейтинг вузов 2014 ARWU [Электронный ресурс] // Сайт «ARWU». URL: http://www. shanghairanking.com/ru/ARWU2014.html (дата обращения: 19.01.2015).

4. Садовничий B.A. // Официальный сайт «РИА Новости». URL: http://ria.ru/edu_higher/ 20120917/ 752274148.html (дата обращения: 19.01.2015).

5. Мировые рейтинги вузов: Великобритания после США [Электронный ресурс] // Сайт «Национальный рейтинг университетов»]. URL: http://www.univer-rating.ru/txt.asp? rbr= 52\&txt=Rbr52Text5227\&lng=0 (дата обращения: 19.01.2015).

6. Кузьминов Я.И. Неприятные рейтинги нам вдвойне полезны 2014 [Электронный ресурс] // Сайт «lenta.ru». URL: http://lenta.ru/articles/2013/12/27/kuzminov/ (дата обращения: 19.01.2015). 
7. Рейтинг Universitas 21 [Электронный pecypc] // Сайт «Eurogates». URL: http://www.eurogates.ru/news/a/ 8095/gollandiya-reiting-universitas-21/ (дата обращения: 19.01.2015).

8. Политика и цели университета в области качества на 2013 - 2015 гг. // Официальный сайт КНИТУ [Электронный ресурc]. URL: http://www.kstu.ru/article.jsp?id=0\&id_e=18335\& (дата обращения: 19.01.2015).

9. Cтуденты назвали главные цели учебы в вузе [Электронный ресурс] // Сайт «CNews». URL: http://rnd.cnews.ru/liberal_arts/news/top/index_science.shtml?2010/01/22/376949 (дата обращения: 04.05.2014).

10.Концепџия экспорта образовательных услуг Российской Федерации на период 20112020 гг. [Электронный ресурс] // Сайт «ЭСM». URL: http://ecsocman.hse.ru/hsedata/2011/01/18/ 1208078939/Concept_for_Exporting.pdf (дата обращения: 19.01.2015).

\section{I.E. Yalovega}

Department of Management and Technology in Higher Professional Education, Institute of Humanities, Social Sciences and Technologies, National Research Tomsk Polytechnic University, Tomsk, Russia.E-mail: yalovegairina@mail.ru

DOI: $10.17223 / 19988648 / 32 / 20$

\section{THE INTERNATIONAL RANKING OF THE HIGHER EDUCATION INSTITUTION:} THE QUALITY OF EDUCATION OR JUDGMENTAL DOMINANCE?

Keywords: Quality of education; Global rankings of higher education institutions; Scientific activity of university; Competitiveness of higher education institutions; Concept of export of the Russian educational services.

What are the best world universities rankings? How do they work? Do they ensure that an institution can attract more students and financial support? Will the cities, where universities are located, get additional economic and social benefits related to jobs and taxes or will they lead to additional promotion of universities that are on a particular ranking, thus enhancing competitiveness of one institution compared to others.

This paper addresses the problem of education quality assessment by means of international higher education institutions rankings. The objective of the paper is to determine whether or not higher education institutions rankings can serve as a tool for assessing the quality of education and whether the implemented set of criteria for including on a ranking reflects the concept of "best university".

With this in mind, the author reviews the criteria, which are used for education quality assessment by different rankings; defines the concept of "best university";

presents criteria options for measuring the "quality" of higher education; determines whether the leading higher education institutions meet the criteria for "best universities" and whether rankings take into account the actual quality of education. The author analyzes the globally recognized rankings of the best universities, which make it possible to conclude that rankings can be considered as objective indicators of quality of higher education and the criteria for including a university on a ranking reflect concept of "the best university". The author also conducts a study of Tomsk higher education institutions graduates and determines how rankings are used by education institutions, entrants and their parents. Finally, the author substantiates the need for presence of Russian universities on international rankings due to implementation of the concept of export of Russian educational services for the period 2011-2020.

\section{References}

1. Times Higher Education. World University Rankings 2014-2015. Available at: http://www.timeshighereducation.co.uk/world-university-rankings/2014-15/world-ranking (accessed 19 January 2015).

2. Topuniversities. QS World University Rankings 2014/15. Available at: http://www. topuniversities.com/university-rankings/world-university-rankings/2014\#sorting=rank+region $=\quad+$ country $=\quad+$ faculty $=+$ stars $=$ false + search $=($ accessed 19 January 2015).

3. Academic Ranking of World Universities 2014. Available at: http://www. shanghairanking.com/ru/ARWU2014.html (accessed 19 January 2015). (In Russian). 
4. RIA Novosti. Sadovnichiy: mezhdunarodnyy reyting vuzov ne otrazhayet urovnya obrazovaniya. Available at: http://ria.ru/edu_higher/20120917/752274148.html (accessed 19 January 2015). (In Russian).

5. Natsional'nyy reyting universitetov. [Global higher education institutions rankings: Great Britain follows the USA]. Available at: http://www.univer-rating.ru/txt.asp?rbr= 52\&txt= Rbr52Text5227\&lng=0 (accessed 19 January 2015).(In Russian).

6. Lenta.ru. Kuz'minov Ya.I. Nepriyatnyye reytingi nam vdvoyne polezny 2014 Available at: http://lenta.ru/articles/2013/12/27/kuzminov/ (accessed 19 January 2015). (In Russian).

7. Eurogates. Universitas 21. Available at: http://www.eurogates.ru/news/a/8095/gollandiyareiting-universitas-21/ (accessed 19 January 2015).

8. Kazan National Research Technological University. [The University's policy and objectives with regard to quality for the period 2013 - 2015]. Available at: http://www.kstu.ru/article.jsp?id= $0 \&$ id $\mathrm{e}=18335$ \& (accessed 19 January 2015). (In Russian).

9. CNews. Studenty nazvali glavnyye tseli ucheby $v$ VUZe. Available at: http:// rnd.cnews. ru/liberal_arts/news/top/index_science.shtml?2010/01/22/376949 (accessed 04 May 2014). (In Russian).

10. [Concept of export of Russian educational services for the period 2011-2020]. Available at: http://ecsocman.hse.ru/hsedata/2011/01/18/1208078939/Concept_for_Exporting.pdf (accessed 19 January 2015). (In Russian).

\section{For referencing:}

Yalovega I.E. Mezhdunarodnyy reyting VUZa: kachestvo obrazovaniya ili sub"yektivnoye dominirovaniye? [The international ranking of the higher education institution: the quality of education or judgmental dominance?]. Vestnik Tomskogo gosudarstvennogo universiteta. Ekonomika - Tomsk State University Journal of Economics, 2015, no. 4 (32), pp. 279-288. 